\title{
Variação do custo da cesta básica no município de Taboão da Serra/SP
}

\author{
Keila Hirle Bremer ${ }^{1}$
}

João Almeida Santos ${ }^{2}$

\begin{abstract}
Resumo
O DIEESE - Departamento Intersindical de Estatística e Estudos Socioeconômicos divulga mensalmente o custo da cesta básica referente a todas as capitais do país. Em algumas cidades que não são abrangidas pela pesquisa, algumas Instituições de ensino, tanto públicas como privadas, realizam a pesquisa e divulgam o resultado. Como o município de Taboão da Serra, localizado na região metropolitana de São Paulo, não possui esses dados divulgados, o presente artigo teve como objetivo identificar o custo mensal e médio da cesta básica e verificar a variação de preços de cada produto que compõe a cesta no município de Taboão da Serra em São Paulo. Partindo de uma lista com as quantidades e os produtos definidos pelo Decreto Lei 399 de 1938 e algumas atualizações, no período de janeiro a junho de 2016 foram pesquisados sete estabelecimentos comerciais e aplicado questionário para um grupo de universitários, com o objetivo de identificar quais produtos são mais consumidos. A metodologia da pesquisa envolve a bibliográfica - para definir os principais conceitos e estado em que o tema se encontra; pesquisa de campo - visita aos pontos de vendas escolhidos para levantar os preços dos produtos e pesquisa quantitativa apenas para destacar os valores em tabelas e gráfico para facilitar a análise e interpretação dos resultados. Um dos resultados aponta que no período de janeiro a junho de 2016 o custo mensal médio da cesta básica em Taboão da Serra/SP foi inferior ao custo divulgado para a cidade de São Paulo no mesmo período pelo DIEESE.
\end{abstract}

Palavras-chave: Cesta básica, Taboão da Serra, Custo.

\begin{abstract}
The DIEESE - Department of Statistics and Socioeconomic Studies publish monthly the cost of the basic hamper referring to all the capitals of the country. In some cities that are not covered by the survey, some educational institutions, both public and private, conduct research and disseminate the result. As the municipality of Taboão da Serra, located in the metropolitan region of São Paulo, does not have this data disclosed, the present article had as objective to identify the monthly and average cost of the basic hamper and to verify the price variation of each product that composes the hamper in the municipality of Taboão da Serra in São Paulo. Starting from a list with the quantities and products defined by Decree Law 399 of 1938 and some updates, in the period from January to June 2016, seven commercial establishments were surveyed and a questionnaire was applied to a group of university students, in order to identify which products are most consumed. The methodology of the

\footnotetext{
${ }^{1}$ Pós-graduanda em controladoria e finanças - centro universitário adventista de São Paulo (UNASP). hirle.keila@gmail.com

${ }^{2}$ Professor dos cursos de graduação administração e contabilidade - Centro Universitário Adventista de São Paulo (UNASP). Professor do curso de pós-graduação: controladoria e finanças - Centro Universitário Adventista de São Paulo (UNASP). professoralmeida2011@gmail.com
} 
research involves the bibliographical - to define the main concepts and state in which the theme is; field survey - visit to selected sales outlets to search product prices and quantitative research only to highlight values in tables and chart to facilitate analysis and interpretation of results. One of the results indicates that in the period from January to June 2016 the average monthly cost of the basic hamper in Taboão da Serra / SP was lower than the cost disclosed to the city of São Paulo in the same period by DIEESE.

Key Words: Basic hamper, Taboão da Serra, Cost.

\section{Introdução}

A Cesta Básica é formada por um grupo de produtos consumidos por uma família mensalmente e tem por objetivo suprir as necessidades de calorias. Por meio do Decreto Lei $\mathrm{n}^{\circ} 399$, de 30 de abril de 1938, foi estabelecido como direito de todo trabalhador brasileiro o salário mínimo. O Decreto define que o salário mínimo é a remuneração devida a todo trabalhador adulto, sem distinção de sexo por dia normal de serviço, capaz de satisfazer, em determinada época e região do país, às suas necessidades normais de alimentação, habitação, vestuário, higiene e transporte (BRASIL. D.L. n 399 art. $2^{\circ}$ ). Como um dos fatores de cálculo do salário mínimo, foi criada a Cesta Básica (GANNE et al, 2015).

Segundo Britto (2007), o valor da cesta básica tem sua relevância assegurada na medida em que se constitui em uma referência da capacidade das famílias adquirirem os itens básicos da alimentação e higiene pessoais. Elevações no custo da cesta básica acima dos ganhos salariais ou acima do crescimento do PIB per capita normalmente estão associadas a períodos de dificuldades sociais.

Como cada região do país possui suas particularidades quanto a plantio, colheita, clima, cultura e outros, o custo da cesta básica pode variar de município para município. Diante disto pergunta-se: no período de janeiro a junho de 2016, qual o valor médio mensal da cesta básica no município de Taboão da Serra, SP?

O DIEESE - Departamento Intersindical de Estatística e Estudos Socioeconômicos divulga mensalmente o custo mensal da cesta básica de todas as capitais brasileiras, demonstrando quanto do salário mínimo é gasto em cada região do Brasil por um trabalhador para se alimentar.

Considerando que a pesquisa realizada pelo DIEESE não divulga dados de Taboão da Serra/SP e, diante do atual cenário econômico, com alto índice de desemprego, inflação em alta e arrocho dos salários, considerando-se ainda que, a cesta básica é um item essencial de 
consumo, pois se refere à sobrevivência das famílias, é relevante o estudo da composição e variação do valor mensal e médio da cesta básica em Taboão da Serra/SP.

Este estudo tem como objetivo identificar o custo mensal e médio da cesta básica no município de Taboão da Serra, no estado de São Paulo e analisar a variação de preços de cada produto que compõe a cesta durante o período pesquisado.

Referente à Metodologia, quanto à abordagem, trata-se de pesquisa quantitativa, pois, de acordo com Richardson (1989), com este método é possível quantificar através de técnicas estatísticas, tanto na fase de coleta de informações quanto no tratamento dos dados coletados. O autor ainda afirma que, com este método, as chances de distorções são reduzidas.

Quanto aos procedimentos, a metodologia utilizada foi pesquisa de campo. Gonsalves (2001) diz que, este tipo de pesquisa busca a informação diretamente com a população pesquisada, ou seja, o pesquisador precisa ir ao espaço onde o fenômeno ocorre, ou ocorreu e levantar as informações a serem documentadas. Também foi utilizada a coleta de dados e, de acordo com Vigorena e Battisti (2011), os procedimentos de coletas de dados são utilizados para investigar o objeto que se pretende conhecer.

Neste estudo, a coleta de dados ocorreu de duas formas. A primeira forma foi a pesquisa de preços dos produtos que compõem a cesta básica definida pelo Decreto Lei no 399 de 1938. Nesta etapa a metodologia utilizada foi similar á metodologia utilizada pelo DIEESE (Departamento Intersindical de Estatística e Estudos Socioeconômicos). Os dados foram coletados em sete estabelecimentos comerciais localizados na cidade de Taboão da Serra, no estado de São Paulo, no período de janeiro a junho de 2016. Os estabelecimentos pesquisados foram 2 supermercados varejistas, 2 supermercados atacadistas, 2 açougues e 1 padaria. Os comércios foram escolhidos considerando a localização estratégica na cidade e a competitividade relevante em relação aos preços.

Para os produtos com marcas, tentou-se sempre considerar três marcas, sendo duas marcas fixas e uma variável. Quando não foi possível manter as duas marcas fixas, buscou-se uma marca similar. Houve momentos que não foi possível a coleta de três marcas para um produto, devido a pouca variedade de marcas desse determinado produto no comércio.

Os preços dos produtos nos estabelecimentos comerciais foram pesquisados sempre uma vez no mês, respeitando-se sempre o mesmo período para os demais meses, ou seja, um 
comércio pesquisado no domingo da primeira semana do mês foi pesquisado sempre no domingo da primeira semana nos demais meses.

A segunda forma de coleta de dados foi feita através de um questionário com 01 pergunta fechada e 01 pergunta aberta, aplicado em um grupo de 77 universitários da região do ABC Paulista e da cidade de São Paulo.

O questionário teve por objetivo identificar a porcentagem de pessoas que utilizam todos os produtos que compõem a cesta básica utilizada pelo DIEESE e quais os produtos que poderiam fazer parte da cesta, na visão dos entrevistados.

Para análise do presente estudo, os dados coletados foram tabulados em planilha (Excel, versão 2013) especificamente elaborada para esse fim, com apresentação gráfica dos resultados.

\section{Fundamentação teórica}

\section{Cesta Básica}

As comissões do salário mínimo, instituídas antes da criação do Decreto Lei no 399 de 30 de abril de 1938, por meio de pesquisas, além de estabelecer os valores mínimos regionais a serem pagos aos trabalhadores também apresentaram uma lista de alimentos e quantidades que seriam suficientes para a sobrevivência de um trabalhador em idade adulta, contendo quantidades balanceadas de proteínas, calorias, ferro, cálcio e fósforo. Os produtos e as quantidades devidas foram agrupados por região (DIEESE, 2009).

Tabela 1. Provisões mínimas estipuladas pelo Decreto Lei no 399

\begin{tabular}{c|c|c|c}
\hline Alimentos & Região 1 & Região 2 & Região 3 \\
\hline Carne & $6,0 \mathrm{~kg}$ & $4,5 \mathrm{~kg}$ & $6,6 \mathrm{~kg}$ \\
\hline Leite & $7,5 \mathrm{I}$ & $6,0 \mathrm{I}$ & $7,5 \mathrm{I}$ \\
\hline Feijão & $4,5 \mathrm{~kg}$ & $4,5 \mathrm{~kg}$ & $4,5 \mathrm{~kg}$ \\
\hline Arroz & $3,0 \mathrm{~kg}$ & $3,6 \mathrm{~kg}$ & $3,0 \mathrm{~kg}$ \\
\hline Farinha & $1,5 \mathrm{~kg}$ & $3,0 \mathrm{~kg}$ & $1,5 \mathrm{~kg}$ \\
\hline Batata & $6,0 \mathrm{~kg}$ & - & $6,0 \mathrm{~kg}$ \\
\hline Legumes (tomate) & $9,0 \mathrm{~kg}$ & $12,0 \mathrm{~kg}$ & $9,0 \mathrm{~kg}$ \\
\hline
\end{tabular}




\begin{tabular}{l|r|r|r}
\hline \multicolumn{1}{c|}{ Pão Francês } & \multicolumn{1}{c|}{$6,0 \mathrm{~kg}$} & \multicolumn{1}{c|}{$6,0 \mathrm{~kg}$} & \multicolumn{1}{c}{$6,0 \mathrm{~kg}$} \\
\hline Café em pó & $600 \mathrm{gr}$ & $300 \mathrm{gr}$ & $600 \mathrm{gr}$ \\
\hline Frutas (banana) & $90 \mathrm{unid}$ & $90 \mathrm{unid}$ & $90 \mathrm{unid}$ \\
\hline Açúcar & $3,0 \mathrm{~kg}$ & $3,0 \mathrm{~kg}$ & $3,0 \mathrm{~kg}$ \\
\hline Banha/Óleo & $750 \mathrm{gr}$ & $\backslash \mathrm{A} 750 \mathrm{gr}$ & $900 \mathrm{gr}$ \\
\hline Manteiga & $750 \mathrm{gr}$ & $750 \mathrm{gr}$ & $750 \mathrm{gr}$ \\
\hline
\end{tabular}

Fonte: DIEESE (2009); Região 1: SP, MG, ES, RJ, GO e DF; Região 2: PB, BA, CE, RN, AL, SE, AM, PA, PI, TO, AC, PB, RO, AM, RR e MA; Região 3: PR, SC, RS, MT e MS.

Nota: não foi divulgado o valor para o item batata na região 2

Vários estudos utilizam a cesta básica como premissa inicial no diagnóstico dos índices de pobreza e distribuição de renda de determinada região. Para Horn (1994), o custo da cesta básica de alimentos constitui, por si só, um parâmetro de pobreza.

No Brasil existem algumas instituições que calculam o preço médio mensal da cesta básica do brasileiro. Pode-se citar como as mais importantes: DIEESE (Departamento Intersindical de Estatísticas e Estudos Socioeconômicos), FGV (Fundação Getúlio Vargas), FIPE (Fundação Instituto de Pesquisas Econômicas), entre outras. Essas instituições divulgam mensalmente o valor da cesta básica para algumas regiões metropolitanas do país. A cidade de Taboão da Serra não é atendida pelos cálculos do valor da cesta básica desses institutos.

Taboão da Serra é um município do Estado de São Paulo, localizado na região Metropolitana de São Paulo, com uma população de 272.177 habitantes (IBGE, 2015). Esta cidade está enquadrada na região 01 da Tabela 1 , definida pelo Decreto Lei $n^{\circ} 399$, utilizada na metodologia do DIEESE.

De acordo com Oliveira (et al, 2013), ainda que seja questionável o fato de existir uma legislação que defina o conjunto de produtos alimentares de uma família, a padronização de critérios nacionais sobre o tema permite a criação de indicadores comparáveis em todo o país e em períodos de tempo diferentes.

\section{Resultados e Discussão}

De acordo com os dados coletados, identificou-se o custo da cesta básica para o município de Taboão da Serra/SP, para cada mês do período pesquisado, janeiro a junho de 2016, conforme o gráfico 1 . 
Gráfico 1. Valor da cesta básica em Taboão da Serra/SP, no período de janeiro a junho de 2016

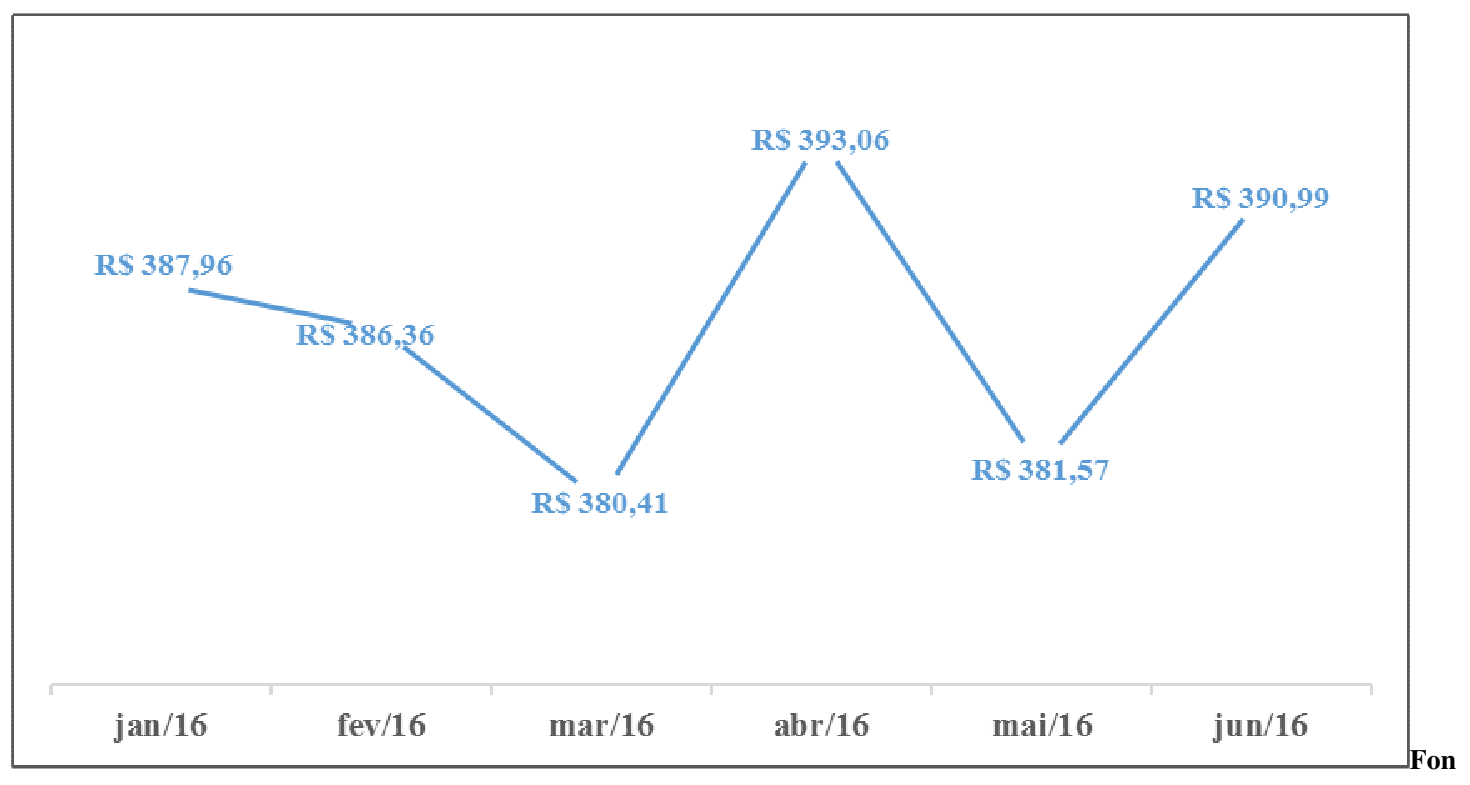

te: Dados da pesquisa.

Analisando o Gráfico 1, percebe-se que o valor da cesta básica em Taboão da Serra, no período pesquisado, oscilou, mas os picos de maior valor da cesta básica foram detectados nos meses de abril e junho.

De acordo com os resultados obtidos, verificou-se que, o custo total mensal médio da cesta básica, no município e período pesquisados, foi de $\mathrm{R} \$ 386,12$. Os dados aferidos demonstram que, um cidadão que sobrevive com um salário mínimo nacional, atualmente R\$ 880,00 , no período de janeiro a junho de 2016 teve quase $50 \%$ de sua renda comprometida (jan-44,01\%, fev-43,9\%, mar-43,2\%, abr-44,07\%, mai-43,04\% e jun-44,4\%).

Ressalta-se que, este valor corresponde apenas a produtos básicos de alimentação, pois a lista de produtos utilizada como parâmetro para a pesquisa, utilizada pelo DIEESE, não considera produtos de limpeza e higiene pessoal, ou seja, o cidadão que sobrevive com um salário mínimo nacional teve quase $50 \%$ de sua renda comprometida apenas com a alimentação básica.

A variação de preço de cada produto que compõe a cesta básica no período pesquisado pode ser observada na Figura 1. 
ReFAE - Revista da Faculdade de Administração e Economia 
Figura 1. Variação do preço de cada produto que compõe a cesta básica em Taboão da Serra/SP, no período de janeiro a junho de 2016
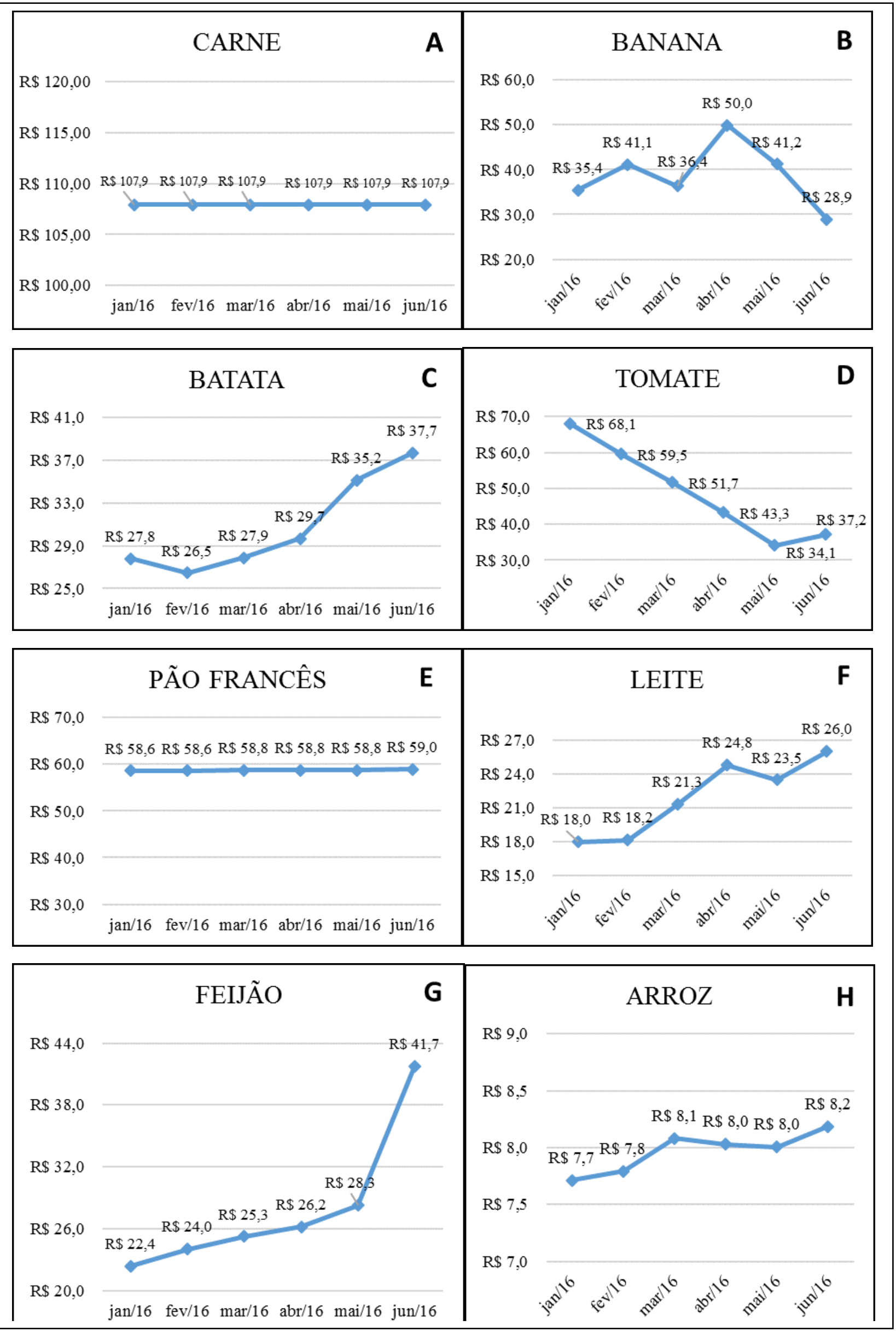


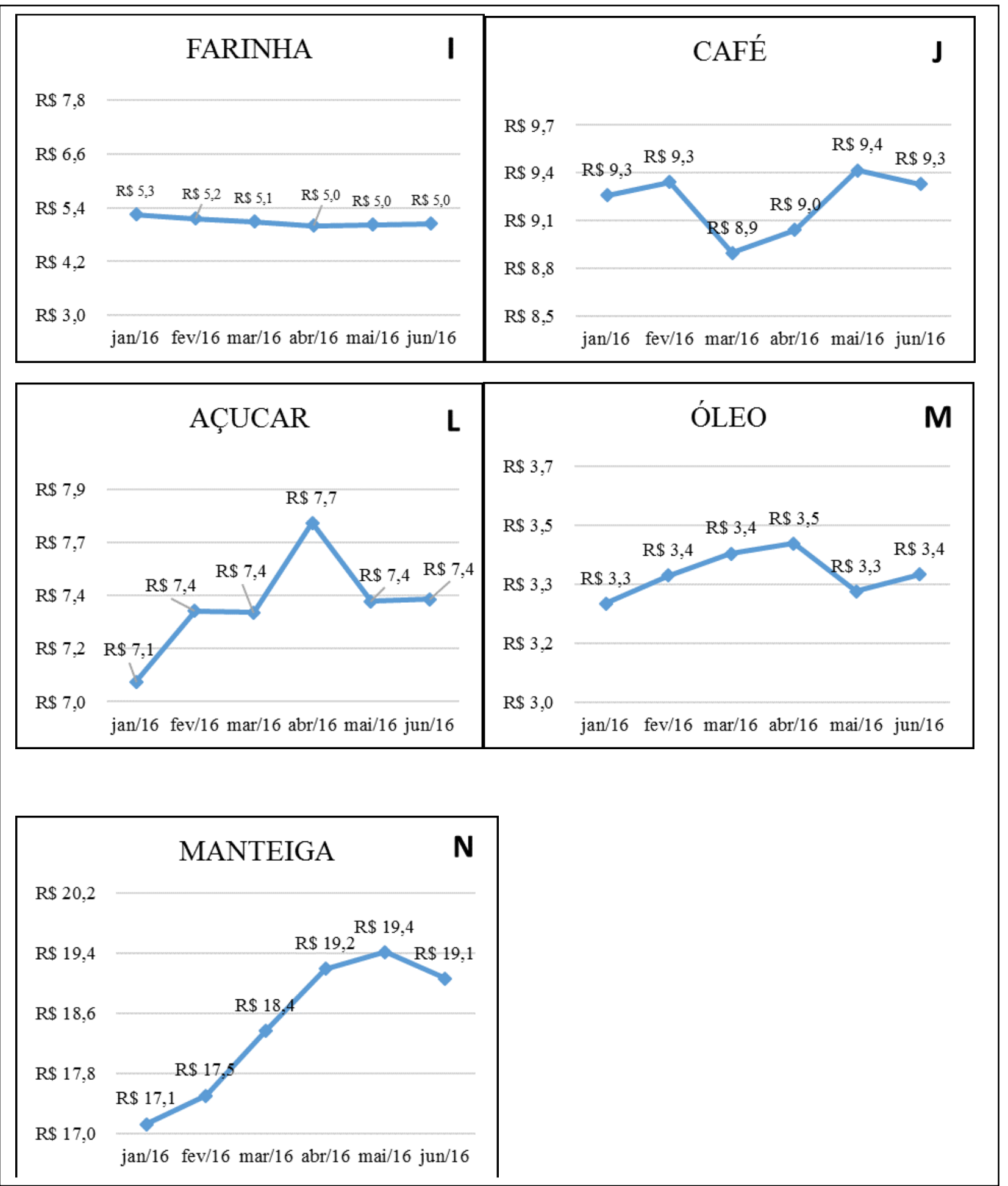

Fonte: Dados da pesquisa.

Verificou-se que, os produtos que mais sofreram alteração de preço no período foram a batata, o tomate e o feijão. O tipo de feijão carioquinha teve um aumento evolutivo de janeiro a maio, mas em junho teve um pico de aumento. Considerando que este é um item indispensável não somente nas mesas dos cidadãos de Taboão da Serra, mas nas mesas brasileiras, ele pesou no momento da escolha dos itens básicos de alimentação. Segundo 
Barros (2016), apesar de poder ser substituído pelo feijão preto, que pode custar R $\$ 1,00$ a menos, ele ainda é o preferido na hora das compras. É mais fácil economizar em outros itens para que o feijão carioquinha permaneça na cesta mensal.

De acordo com Uribe e Cucolo (2016), o produto teve grande alta em junho devido à quebra da safra por questões climáticas que levaram a perda de grande parte da safra no Centro Oeste, ocasionando diminuição da oferta e aumento da demanda.

O tomate começou o ano com o valor em alta, mas durante os meses posteriores o preço sofreu redução e alcançou em maio/junho uma leve estabilização. De acordo com dados coletados no CEAGESP pela equipe Hortifruti/CEPEA, no mês de janeiro o preço do tomate salada atingiu o patamar mais alto nesse mesmo período, desde 2002. A principal explicação é a de que a oferta do fruto no mercado foi bem reduzida. Outro fator foi a chuva, que provocou manchas no tomate, diminuindo a qualidade e reduzindo as vendas (JÚNIOR; MOLENA; SÁBIO, 2016).

A batata apresentou leve redução no preço no mês de fevereiro, mas nos meses seguintes registrou aumento constante. A variação seguiu a pesquisa realizada pelo DIEESE (2016) para a cidade de São Paulo, divulgada mensalmente em seu site. A pesquisa do DIEESE também apontou redução no preço da batata no mês de fevereiro e aumento do preço nos meses seguintes, março, abril, maio e junho/2016.

Abaixo consta a representação de cada item no custo total da cesta básica no último mês do período pesquisado, junho/2016. 
Gráfico 2. Representação do custo de cada item no custo total da cesta básica de Taboão da Serra, em junho de 2016.

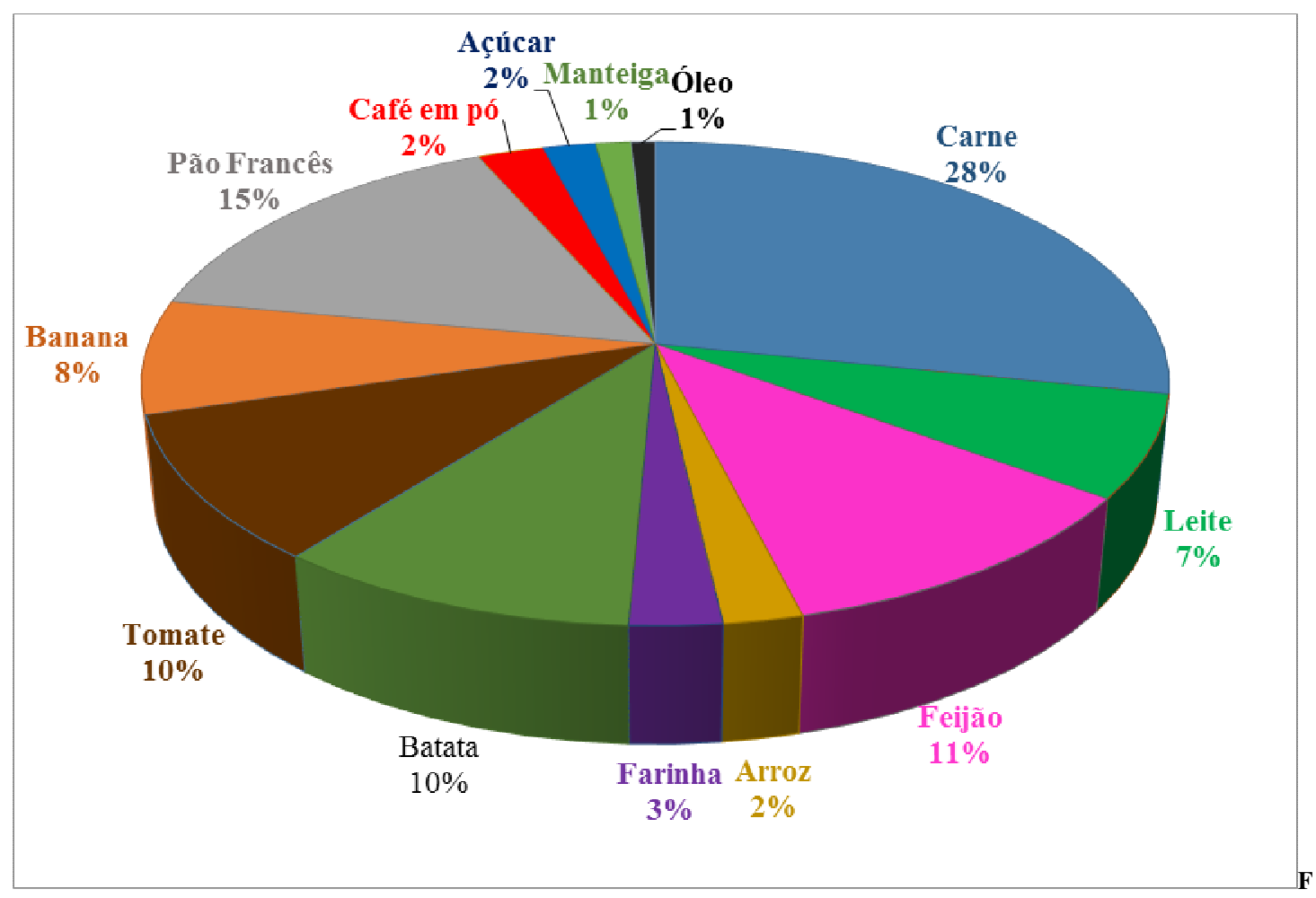

onte: Dados da pesquisa.

Conforme verificado, no custo total da cesta básica, cada produto teve sua representatividade de acordo com a oscilação de preço. Em ordem de maior relevância, os produtos representaram na cesta básica: $28 \%$ - carne, $15 \%$ - pão francês, $11 \%$ - feijão, 10\% batata, $10 \%$ - tomate, $8 \%$ - banana, $7 \%$ - leite, 3\% - farinha, 2\% - café em pó, $2 \%$ - açúcar, $1 \%$ - manteiga, $1 \%$ - óleo.

De acordo com o jornal Sarzedas (2016), a crise econômica fez com que os cidadãos brasileiros diminuíssem o consumo da carne vermelha. Apesar dos preços não terem apresentado elevação no período de janeiro a junho deste ano, o recuo no consumo continua em função da queda do poder aquisitivo da população.

A segunda etapa da pesquisa foi feita em forma de questionário aplicado em um grupo de 77 pessoas universitários, 40 mulheres e 37 homens.

Dos entrevistados, 55\% afirmaram que utilizam todos os produtos que compõem a cesta básica. Tal resultado indica que, os itens utilizados na cesta básica do DIEESE, para 
mais de 50\% dos entrevistados, são essenciais. O restante dos entrevistados utilizavam 12 ou menos produtos da cesta básica do DIEESE, que é composta por 13 itens alimentícios.

Foi solicitado a este grupo de pessoas que citassem 03 produtos que consideravam essenciais à cesta básica, mas que não constavam na lista da cesta básica do DIEESE. Conforme segue no gráfico abaixo, os produtos mais citados, em ordem de maior citação foram: macarrão, achocolatado, sal, biscoito, ovo, frango e temperos.

\section{Gráfico 3. Produtos mais citados para compor a cesta básica}

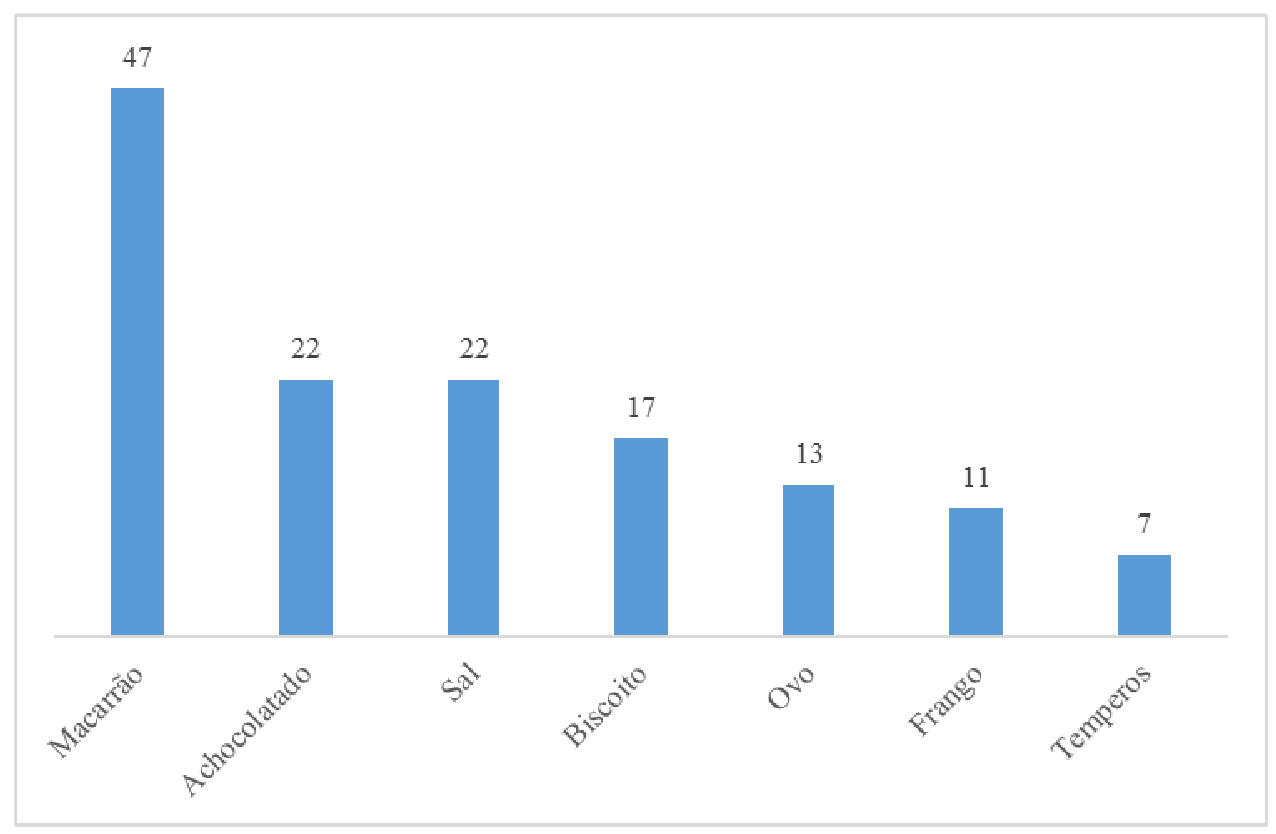

Fonte: Dados da pesquisa.

Apesar de já constar arroz e carne de boi na lista de alimentos da cesta básica, foram sugeridos macarrão e carne de frango, como também itens essenciais a uma cesta básica, sendo o item macarrão o mais citado pelos entrevistados.

\section{Considerações Finais}

Com base nos resultados obtidos, verificou-se que, em Taboão da Serra/SP, no período de janeiro a junho de 2016 o custo mensal médio da cesta básica foi inferior ao custo divulgado para a cidade de São Paulo no mesmo período pelo DIEESE, R\$ 449,49. Mas apesar de ter sido inferior a de São Paulo, a parcela gasta com alimentação pelos cidadãos de 
Taboão da Serra foi alta, o equivalente a quase $50 \%$ do valor do salário mínimo nacional, atualmente $\mathrm{R} \$ 880,00$.

Os produtos que apresentaram maior elevação de preço no período pesquisado foram a batata, o tomate e o feijão. Isso ocorreu, principalmente, devido a questões climáticas que afetou a qualidade dos produtos e a oferta, atingindo diretamente o preço final para o consumidor.

A carne se mostrou como o produto de maior representatividade na cesta básica. Verificando o seu preço e a quantidade prevista de consumo (conforme tabela utilizada como parâmetro), do valor gasto com a cesta básica, $28 \%$ o cidadão empregaria para adquirir a carne vermelha.

Na segunda etapa da pesquisa, os resultados apontaram que, 55\% dos entrevistados compram todos os produtos que compõem a lista da cesta básica. Isso demonstra a relevância dos produtos listados e confirma que a lista utilizada ainda é atual.

Como sugestão para compor a cesta básica, o macarrão foi o produto mais citado. $\mathrm{Na}$ região sudeste, esse produto pode ser observado na mesa da população como um prato principal, e se apresenta como um produto de baixo custo, motivos pelos quais se explica o primeiro lugar no Ranking das sugestões.

A pesquisa conseguiu atingir seus objetivos, tendo ela identificado o custo total mensal e médio da cesta básica e a variação de preços de cada produto que compõe a cesta durante o período pesquisado no município de Taboão da Serra/SP. Mas o estudo pode ser continuado, tendo em vista a divulgação mensal fixa do preço da cesta básica neste município. Este trabalho daria base para pesquisas e análises de estudantes de diversas áreas, mas também auxiliaria a população, grupo mais interessado no assunto. Muitas instituições de ensino, públicas, fazem um trabalho eficiente na divulgação do valor da cesta básica em cidades que não são abrangidas pelo DIEESE e, partindo dessas situações, poderia se trabalhar com o propósito de atingir esse objetivo no município de Taboão da Serra, SP.

\section{Referências}

BARROS, J. C. Preço do feijão aumenta a cesta básica. Agora, São Paulo, 02 de maio de 2016, Grana. 
Brasil. Decreto Lei n ${ }^{\circ} 399$, de 30 de outubro de 1938. Diário Oficial da República Federativa do Brasil. Poder Executivo, Brasília, DF, 30 out. 1938.

BRITTO, E. M. O. Analisando relações entre variáveis para justificar o valor gasto com cesta básica nas principais regiões brasileiras. São Paulo. 2007. 29 p. Programa de Estudos Pós-Graduados em Administração-Faculdade de Economia e Administração, Pontífica Universidade Católica de São Paulo. São Paulo, 2007. Disponível em:

$<$ http://www.pucsp.br/sites/default/files/download/posgraduacao/programas/administracao/ba sta/1s2007/Elaine.pdf>. Acesso em: 19 de dezembro de 2015.

\section{DEPARTAMENTO INTERSINDICAL DE ESTATÍSTICA E ESTUDOS SÓCIO- ECONÔMICOS - DIEESE. 2009. Disponível em <http://}

http://www.dieese.org.br/metodologia/2009/metodologiaCBNAtualizacao.pdf>. Acesso em: 20 de dezembro de 2015.

15 de fevereiro de 2016. Disponível em <http://

https://www.dieese.org.br/metodologia/metodologiaCestaBasica.pdf $>$. Acesso em: 20 de dezembro de 2015.

GANNE, N.; GALEANO, R. D.; JÚNIOR, R. C. V. A.; FERNANDEZ, E. S.; CANCIAN, G. T.; SOUZA, J. H. M.; GARCIA, L. S. S. Estudo sobre o comportamento de preços de produtos da cesta básica 2014/2015: Supermercados da cidade de Corumbá, Mato Grosso do Sul, Brasil. Universidade Federal de Mato Grosso do Sul - Pesquisa de Preços de Produtos da Cesta Básica - Curso de Administração, Corumbá, MS. 03 de Julho 2015. Disponível em: <http://cpan.sites.ufms.br/files/2015/07/ARTIGO-PESQUISA-DEPRE\%C3\%87OS-2014-2015.pdf>. Acesso em: 13 de março de 2015.

GONSALVES, E. P. Conversas sobre iniciação à pesquisa científica. Campinas, SP: Alínea, 2001.

URIBE, G.; CUCOLO, E. Para baixar o preço do feijão, Temer quer aumentar importação do Mercosul. Folha de São Paulo, Brasília, 22 de jun. 2016. Folha Mercado. Disponível em:< http://www1.folha.uol.com.br/mercado/2016/06/1784278-para-baixar-preco-do-feijao-temeranuncia-aumento-da-importacao-de-paises-do-mercosul.shtml>. Acesso em: 12 de julho de 2016.

HORN, C.H. Pobreza e mercado de trabalho: cálculo de uma linha de pobreza absoluta para a região metropolitana de Porto Alegre. Indicadores Econômicos FEE, v. 23, n. 1, p. 185-200, 1994. Disponível em:< http://revistas.fee.tche.br/index.php/indicadores/article/view/624/869>. Acesso em: 14/07/2016.

INSTITUTO BRASILEIRO DE GEOGRAFIA E ESTATÍSTICA - IBGE. Diretoria de Pesquisas - DPE - Coordenação de População e Indicadores Sociais - COPIS. 2015. Disponível em:

$<$ http://cidades.ibge.gov.br/xtras/perfil.php?lang=\&codmun=355030\&search=|linfográficos:informações-completas>. Acesso em: 15 de março de 2016.

JÚNIOR, J.; MOLENA, L.; SÁBIO, R. P. Cotações do tomate em alta. HF Brasil, 2016. Disponível em: < http://www.hfbrasil.org.br/cotacoes-do-tomate-em-alta.aspx>. Acesso em: 12 de julho de 2016. 
OLIVEIRA, S. K.; SANTOS, V. M.; SANTINI, M. M.; SUZIN, P. T.; BOSCHI, G. C. Influência da inflação nos produtos da cesta básica no primeiro semestre de 2013. In: Anais VII Seminário de Iniciação Científica Curso Ciências Contábeis da Faculdade da Serra Gaúcha, 2013. Faculdade da Serra Gaúcha. Caxias do Sul, RS. Disponível em: < http://ojs.fsg.br/index.php/anaiscontabeis/article/viewFile/450-459/781>. Acesso em: 14 de março de 2016.

RICHARDSON, R. J. Pesquisa Social: métodos e técnicas. $3^{\text {a }}$ Ed. São Paulo: Atlas, 1989.

SARZEDAS, V. Crise derruba consumo de carnes no Brasil. Agora, São Paulo, 20 de jul. 2016. Grana. Disponível em:< http://www.agora.uol.com.br/grana/2016/07/1793459-crisederruba-consumo-de-carnes-no-brasil.shtml>. Acesso em: 24 de julho de 2016.

VIGORENA, D. A. L.; BATTISTI, P. S. S. Procedimentos de coleta de dados em trabalhos de conclusão do curso de Secretariado Executivo da Unioeste/PR. Revista do Secretariado Executivo, Passo Fundo, PR, n. 7, p. 95-111, 2011. Disponível em:< http://www.upf.br/seer/index.php/ser/article/view/2329/1483>. Acesso em: 21 de março de 2016. 